\title{
NURSES' PERCEPTION ABOUT PATIENT SAFETY CULTURE IN DUHOK HOSPITALS
}

\author{
RONAK HASSAN BARWARI \\ College of Nursing, University of Duhok, Kurdistan Region -Iraq
}

(Received: May 25, 2021 ; Accepted for Publication: September 8, 2021)

\begin{abstract}
Background: Patient safety is one of the vital aspects that integrated to the health care system and patients' outcomes. It is crucial to focus on the concept of patient safety to improve the health care services and the quality of care. The study was conducted to identify the variations in nurses' safety attitudes based on their demographics.

Methods: This is a cross-sectional study conducted among 100 nurses working in teaching hospitals at Duhok City/ Kurdistan region/Iraq. The data was collected using two parts survey: The Safety Attitude questionnaire and the demographics. The data were analyzed using the SPSS statistical software ver. 24, which included descriptive and inferential statistical analysis with a $P$-values $\leq 0.05$.

Findings: The study revealed that there was a statistically significant difference in nurses' safety attitudes based on their level of education. The level of education and team working were correlated, and a significant correlation was found between working conditions and with nurses' experience. Moreover, the study represented that there is no significant correlation between leadership role with safety variables.

Conclusions: It is crucial to assess the factors that contribute to patients safety. To improve the quality of care and safety attitude, nurse leaders and stakeholders play an important role. Nurse leaders support the safe environment at the units of care. Moreover, focusing on achieving a higher level of education is crucial and recommended to enhance the Patients outcomes.
\end{abstract}

KEY WORDS: Patient Safety, Safety Culture, Nurses Perception, Patients' outcomes, Work Environment

\section{BACKGROUND}

$\mathbf{N}$ owadays, Patient safety is a core element in the health care system (Kangasniemi et al., 2013). Patient safety is defined as absence of patient's harm while receiving healthcare services, and it is the prevention of errors, near misses, and adverse events that might be caused by the health care providers (Kangasniemi et al., 2013; Nieva \& Sorra, 2003; Tondo \& de Brito Guirardello, 2017). The importance of patient safety is one of the references of the Institute of Medicine to improve the patient safety culture (El-Jardali et al., 2011). The number of adverse event is high and it is influenced by the degree of safety measures that are provided in health care institutions (Tavares et al., 2018). The statistics indicate that adverse event is about $10 \%$ of the total admission in developed countries and lesser in the developing countries. As well as there is a positive correlation between a safe environment and patients' outcomes (Sharour et al., 2018).

There is an integration between patient safety and safety culture. Safety culture is represented in various concepts such as attitudes, beliefs, values, and assumptions that surrounded health care providers' organizations (Sharour et al., 2018; Lee et al., 2010). The transforming organizational culture is one of the focuses of Healthcare organizations to ensure patient safety (Lee et al., 2010). Safe practice is affected by the safety values of nurses (Kangasniemi et al., 2013). Based on previous studies, many factors associated with the safety at health care settings such as the safe climate, moral aspects between staff, staff number, the role of leaders' support, training courses, teamwork climate, job satisfaction, working environment and satisfaction (Sharour et al.,2018). Safety culture is one of the important factor that influences system safety (Elsous et al., 2017; Vincent, Taylor-Adams, \& Stanhope, 1998). Safety 
culture is a critical aspect that needs to be more focused on and studies by health care leaders, the leadership plays a significant role and accountability key to enhance and improve the culture of safety (Kangasniemi et al., 2013; Sammer et al., 2010). Nurses perceptions of safety culture is important to provide explanation regarding health errors and patient safety culture (Kim, et al., 2007).

Nurse leaders have a crucial role in enhancing patient safety and quality improvement in healthcare settings. They must work to engage health care providers to participate in safety and quality improvement, they need to be knowledgeable in quality and safety. Also, leaders can improve the outcomes of organizations by creating a culture of safety (Jeffs, et al., 2018). Because safety culture perception is varied among health care employees (Li et al., 2018), and there is little known about the safety culture at our hospitals; therefore, the researcher conducted this study to identify the surrounded factors that correlate and interfere with safety culture. As well as nurses' perception toward patient safety at their health care institutes.

\section{METHODS}

A cross-sectional study was conducted among randomly-selected nurses from different units of three teaching hospitals in Duhok City. After the ethical permission was obtained from the directorate of health/ Duhok city/ Kurdistan Region/ Iraq, the nurses were interviewed and explained about the study, recruitment process, confidentiality, and their rights to participate or refuse the participation in the study. From all interviewed nurses, 100 nurses participanted in the study. The information that the participants provided in this study is kept confidential by coding participants with numbers. The recruitment was conducted through informed consent, so those who agreed to participated were interviewed and participated. The eligibility criteria were bedside nurses who have at least one year of experience in different units. The data collection started from May 2020 to November 2020.

\section{INSTRUMENTATION}

The Safety attitude Questionnaire (SAQ) was used to conduct this study. Nurses' attitude toward safety measures at their unit was measured using a 6-point 32-item Likert scale that was developed by the author of the questionnaire (Sexton, Thomas, \& Grillo, 2003). Permission was obtained from the developer to use the questionnaire. An example item was, "In this clinical area, it is difficult to speak up if I perceive a problem with patient care." Responses ranged from 0(Disagree strongly) to 100 (agree strongly). The Questionnaire is divided in to six sub-domain which are team work climate (items 1 to 6), (safety climate items 7 to 14), (job satisfaction items 15 to 19), (stress recognition items 20 to 23), (perceptions of management items 24 to 28), and (working conditions items 29 to 32). Participants' demographic information was assessed using a short survey that included questions regarding participants' age, department, education level, employment status, and experience.

Data analysis was conducted using SPSS statistical software (version 24.0). Descriptive statistics were used to summarize the demographic characteristics of the participants such as frequency, mean, and standard deviation. To determine how nurses differ in their perceived levels of the safety culture based on their demographic characteristics. Pearson's correlation coefficient was used to examine how the continuous demographic factors, such as age and experience, were related to nurses' perception of hospital safety. One-way ANOVA was used to compare means of safety attitude categories among nurses.

\section{RESULTS}

One hundred nurses were participated in the study and responded to the questionnaires. The median of age was 28.0. The percentage of male nurses was $56 \%$ and from different departments or units. About three quarters of the nurses are a high school of nursing graduated (62\%). Only $10 \%$ of the nurses are nurse managers and 55\% of them were married (Table 1).

Table 2 details the mean and (SD) for the safety attitude sub-domains. The highest mean score was 3.9 for the job satisfaction subdomain. To identify the correlation between safety attitude sub domains and nurses' sociodemographic characteristics, table 
3 shows that a significant correlation between team working score with educational level (p.0.008). Also, there was a significant correlation between working conditions sub domain with years of experience in general ( $p$. 0.005).

\section{DISCUSSION}

Patient safety is one of the basic principles in improving the quality of care, health care services, and patient satisfaction. Patient safety interferes with the improvement of safety culture in the health care settings (Zarei et al., 2014). Nurses' education plays a significant role in improving nurses' commitment to consider safety as one of the principles to provide better quality of care. Nurses with higher education gain more knowledge and skills toward the importance of safety in nursing practice. Align with our results, Aram et al., (2018) found a significant relationship between education and safety attitude in their study. Also, education is considered as one of the most important factors affecting nurses' attitude. One of the important components of patients safety is teamwork (Kim, et al., 2007). The team working climate was difference between nurses based on their level of education. Aram et al., (2018) found a significant relationship between work experience and participants' safety attitude. However, in a study conducted by Bondevik et al., (2017), the years of experience were not associated with the safety factors. Our study showed that the age of nurses was not associated with the mean scores for the patient safety factors. However, age was associated significantly with some safety variables (Bondevik et al., 2017). With increasing in nurses' experience, their perception about the role of nurse manager and leaders in supporting and enhancing patient safety increases.

Our study supports the fact that working condition of nurses affect their safety perception positively and it is significantly correlated with the safety attitude. Nurse managers plays a significant role in enhancing patient safety (Kangasniemi et al., 2013). The involvement of stakeholders and managers in supporting the safety culture is crucial and they maintain and support safety culture assessment and implementation (Bahrami, et al., 2014; Nieva \& Sorra, 2003; Gunawan, \& Tutik Sri Hariyati, 2019). Patient safety remains a crucial topic to solve because it is not simply a technical issue, it is a practice issue in different contexts such as professional and organizational (Rowland \& Kitto, 2014). A group of factors such as mature safety, safety culture, and patient safety work together in improving patient outcomes (Lee et al., 2010). Considering the importance of job satisfaction, this study revealed that job satisfaction had the highest mean 3.9 score regarding the safety culture. Nurses' satisfaction enhances the safety and patients' outcomes which is congruent with the results of (Sharour et al., 2018). Interventions are crucial to improve the safety culture perceptions and reduce patient harm (Weaver et al., 2013).

Limitation of the study include a small sample size, new topic to be considered by our nurses, and inability to represents improving in safety culture and patients' outcomes.

\section{CONCLUSION}

The study revealed that patient safety culture is crucial for all health care providers especially for nurses. Nurses' level of education, age, and years of experience play important role in patient safety culture and nurses' considerations. Patient safety needs to be considered by health care organizations and nurse leaders to provide better quality of care and enhance patients' outcomes. Hospitals attitude improvement towards patient safety culture is important to be implemented by supporting all dimensions of a positive safety culture.

Implications for Occupational Health Nursing Practice: 
It is crucial to focus on the aspects of safety at health care settings and the factors that enhance and eliminate safety. Nurse leaders should focus on the aspects of safety and track changes of culture safety at their clinical units. Hospitals and health care facilities need to shift toward elements of safety culture and take appropriate actions to enhance patients' outcomes.

Table (1):-General characteristic of nurses

\begin{tabular}{lll}
\hline Demographics characteristics $(\mathbf{n}=\mathbf{1 0 0})$ & Statistics & IQR \\
\cline { 2 - 3 } & Median & 7.0 \\
\hline Age (Range 21-50 years) & 28.0 & 1.0 \\
\hline Experience in current area (Range: 1 -3 years) & 1.0 & 1.0 \\
\hline Experience in general (Range: 1-3 years) & 1.0 & 44 \\
\hline Sex & No & 56 \\
Female & 44 & 13.0 \\
Male & 56 & 21.0 \\
\hline Clinical Department & 13 & 10.0 \\
Emergency Room & 21 & 13.0 \\
Cardiology and cardiac center & 10 & 25.0 \\
Oncology & 13 & 7.0 \\
CCU and ICU & 25 & 11.0 \\
Medical ward & 7 & 7.0 \\
Neurology & 11 & 62.0 \\
Urology and Dialysis & & 29.0 \\
\hline Education level & 7 & 2.0 \\
Secondary Nursing School & 62 & 10 \\
High School of Nursing & 29 & 45.0 \\
Bachelor of Science in Nursing & 2 & 55.0 \\
Master of Science in Nursing & & \\
\hline Nurse Manager & 10 & 45 \\
\hline Marital status & 55 & \\
Single & & \\
Married & & \\
\hline Tables: & & \\
\hline
\end{tabular}

Tables:

Note. IQR: Interquartile range

Table( 2):-Mean scores\& Standard deviation of safety attitudes among nurses

Categories Mean Std. Deviation

\begin{tabular}{lll}
\hline Team Working Score & 3.8 & 0.5 \\
\hline Safety Culture Score & 3.3 & 0.5 \\
\hline Job Satisfaction Score & 3.9 & 0.8 \\
\hline Stress Recognition Score & 2.8 & 0.8 \\
\hline Perception of Management Score & 3.5 & 0.6 \\
\hline Working Conditions Score & 3.6 & 0.8 \\
\hline Total Score & 3.5 & 0.4 \\
\hline
\end{tabular}

Table( 3):-Correlation of safety attitudes categories with socio-demographic aspects of nurses 
Journal of University of Duhok, Vol. 24, No.2 (Pure and Eng. Sciences), Pp 36-42, 2021

\begin{tabular}{|c|c|c|c|c|}
\hline Controlling factors & Dependent Variables & Mean Square & $\begin{array}{l}\text { F Score } \\
\quad(n=100)\end{array}$ & P-value \\
\hline Gender & $\begin{array}{r}\text { Team Working Score } \\
\text { Safety Culture Score } \\
\text { Job Satisfaction Score } \\
\text { Stress Recognition Score } \\
\text { Perception of Management Score } \\
\text { Working Conditions Score }\end{array}$ & $\begin{array}{l}0.152 \\
0.222 \\
0.744 \\
0.260 \\
1.086 \\
0.000\end{array}$ & $\begin{array}{l}0.648 \\
1.067 \\
1.051 \\
0.430 \\
3.382 \\
0.000\end{array}$ & $\begin{array}{l}0.423 \\
0.304 \\
0.308 \\
0.514 \\
0.069 \\
0.988\end{array}$ \\
\hline Educational Level & $\begin{array}{r}\text { Team Working Score } \\
\text { Safety Culture Score } \\
\text { Job Satisfaction Score } \\
\text { Stress Recognition Score } \\
\text { Perception of Management Score } \\
\text { Working Conditions Score }\end{array}$ & $\begin{array}{l}0.973 \\
0.151 \\
1.577 \\
0.284 \\
0.239 \\
0.472\end{array}$ & $\begin{array}{l}4.151 \\
0.725 \\
2.228 \\
0.470 \\
0.743 \\
0.823\end{array}$ & $\begin{array}{l}0.008 \\
0.540 \\
0.090 \\
0.704 \\
0.529 \\
0.485\end{array}$ \\
\hline Marital Status & $\begin{array}{r}\text { Team Working Score } \\
\text { Safety Culture Score } \\
\text { Job Satisfaction Score } \\
\text { Stress Recognition Score } \\
\text { Perception of Management Score } \\
\text { Working Conditions Score }\end{array}$ & $\begin{array}{l}0.012 \\
0.197 \\
3.292 \\
0.003 \\
0.016 \\
0.012\end{array}$ & $\begin{array}{l}0.053 \\
0.944 \\
0.000 \\
0.004 \\
0.051 \\
0.021\end{array}$ & $\begin{array}{l}0.819 \\
0.334 \\
0.995 \\
0.947 \\
0.821 \\
0.885\end{array}$ \\
\hline Nurse Manager & $\begin{array}{r}\text { Team Working Score } \\
\text { Safety Culture Score } \\
\text { Job Satisfaction Score } \\
\text { Stress Recognition Score } \\
\text { Perception of Management Score } \\
\text { Working Conditions Score }\end{array}$ & $\begin{array}{l}0.016 \\
0.002 \\
0.138 \\
0.479 \\
0.002 \\
0.527\end{array}$ & $\begin{array}{l}0.069 \\
0.008 \\
0.195 \\
0.792 \\
0.008 \\
0.919\end{array}$ & $\begin{array}{l}0.793 \\
0.929 \\
0.660 \\
0.376 \\
0.931 \\
0.340\end{array}$ \\
\hline Age & $\begin{array}{r}\text { Team Working Score } \\
\text { Safety Culture Score } \\
\text { Job Satisfaction Score } \\
\text { Stress Recognition Score } \\
\text { Perception of Management Score } \\
\text { Working Conditions Score }\end{array}$ & $\begin{array}{l}0.196 \\
0.000 \\
0.735 \\
0.220 \\
0.005 \\
0.365\end{array}$ & $\begin{array}{l}0.834 \\
0.001 \\
1.038 \\
0.363 \\
0.017 \\
0.637\end{array}$ & $\begin{array}{l}0.363 \\
0.980 \\
0.311 \\
0.548 \\
0.897 \\
0.427\end{array}$ \\
\hline Experience general unit & $\begin{array}{r}\text { Team Working Score } \\
\text { Safety Culture Score } \\
\text { Job Satisfaction Score } \\
\text { Stress Recognition Score } \\
\text { Perception of Management Score } \\
\text { Working Conditions Score }\end{array}$ & $\begin{array}{l}0.391 \\
0.004 \\
0.932 \\
0.197 \\
0.172 \\
4.665\end{array}$ & $\begin{array}{l}1.669 \\
0.019 \\
1.316 \\
0.325 \\
0.535 \\
8.134\end{array}$ & $\begin{array}{l}0.200 \\
0.892 \\
0.254 \\
0.570 \\
0.466 \\
0.005\end{array}$ \\
\hline
\end{tabular}

Table (4):-Comparison of means of safety attitude categories among nurses with different education levels Safety attitude categories $(n=100) \quad$ Mean Std. Deviation P-value

\begin{tabular}{lllll}
\hline Team Working Score & Secondary Nursing School & 4.0 & 0.4 & 0.007 \\
& High School of Nursing & 3.9 & 0.4 & \\
& Bachelor of Science in Nursing (BSN) & 3.5 & 0.6 & 0.2 \\
& Master of Science in Nursing & 3.7 & 0.4 & 0.506 \\
& Secondary Nursing School & 3.2 & 3.4 & \\
\hline Safety Culture Score & High School of Nursing & 3.3 & 0.6 & \\
& Bachelor of Science in Nursing (BSN) & 3.3 & 0.1 & 0.6 \\
& Master of Science in Nursing & 4.1 & 0.9 & 0.122 \\
& Secondary Nursing School & 4.0 & 0.9 & \\
\hline
\end{tabular}


Journal of University of Duhok, Vol. 24, No.2 (Pure and Eng. Sciences), Pp 36-42, 2021

\begin{tabular}{|c|c|c|c|c|}
\hline & $\begin{array}{l}\text { Bachelor of Science in Nursing (BSN) } \\
\text { Master of Science in Nursing }\end{array}$ & $\begin{array}{l}3.7 \\
3.2\end{array}$ & $\begin{array}{l}0.8 \\
1.1\end{array}$ & \\
\hline \multirow{4}{*}{ Stress Recognition Score } & Secondary Nursing School & 2.7 & 0.3 & \multirow{4}{*}{0.438} \\
\hline & High School of Nursing & 2.7 & 0.7 & \\
\hline & Bachelor of Science in Nursing (BSN) & 3.0 & 0.9 & \\
\hline & Master of Science in Nursing & 2.9 & 0.9 & \\
\hline \multirow{4}{*}{$\begin{array}{l}\text { Perception of Management } \\
\text { Score }\end{array}$} & Secondary Nursing School & 3.8 & 0.5 & \multirow[t]{4}{*}{0.354} \\
\hline & High School of Nursing & 3.4 & 0.5 & \\
\hline & Bachelor of Science in Nursing (BSN) & 3.4 & 0.7 & \\
\hline & Master of Science in Nursing & 3.7 & 0.4 & \\
\hline \multirow[t]{4}{*}{ Working Conditions Score } & Secondary Nursing School & 3.8 & 0.6 & \multirow[t]{4}{*}{0.271} \\
\hline & High School of Nursing & 3.7 & 0.7 & \\
\hline & Bachelor of Science in Nursing (BSN) & 3.3 & 0.9 & \\
\hline & Master of Science in Nursing & 3.4 & 1.2 & \\
\hline \multirow[t]{4}{*}{ Total Score } & Secondary Nursing School & 3.6 & 0.3 & \multirow[t]{4}{*}{0.252} \\
\hline & High School of Nursing & 3.5 & 0.3 & \\
\hline & Bachelor of Science in Nursing (BSN) & 3.3 & 0.5 & \\
\hline & Master of Science in Nursing & 3.4 & 0.3 & \\
\hline
\end{tabular}

Note. -One way ANOVA test was performed for statistical analyses.

Table 5:-Correlation of safety attitude categories with general experiences of nurses

\begin{tabular}{|c|c|c|}
\hline Safety attitude categories $(n=100)$ & Experience gel & \\
\hline Team Working Score & $\begin{array}{l}\text { Pearson Correlation } \\
\text { Sig. (2-tailed) }\end{array}$ & $\begin{array}{l}-0.023 \\
0.819 \\
\end{array}$ \\
\hline Safety Culture Score & $\begin{array}{l}\text { Pearson Correlation } \\
\text { Sig. (2-tailed) }\end{array}$ & $\begin{array}{l}0.088 \\
0.384\end{array}$ \\
\hline Job Satisfaction Score & $\begin{array}{l}\text { Pearson Correlation } \\
\text { Sig. (2-tailed) }\end{array}$ & $\begin{array}{l}-0.014 \\
0.892 \\
\end{array}$ \\
\hline Stress Recognition Score & $\begin{array}{l}\text { Pearson Correlation } \\
\text { Sig. (2-tailed) }\end{array}$ & $\begin{array}{l}0.019 \\
0.852 \\
\end{array}$ \\
\hline Perception of Management Score & $\begin{array}{l}\text { Pearson Correlation } \\
\text { Sig. (2-tailed) }\end{array}$ & $\begin{array}{l}0.157 \\
0.118 \\
\end{array}$ \\
\hline Working Conditions Score & $\begin{array}{l}\text { Pearson Correlation } \\
\text { Sig. (2-tailed) }\end{array}$ & $\begin{array}{l}0.339^{* *} \\
0.001\end{array}$ \\
\hline Total Score & $\begin{array}{l}\text { Pearson Correlation } \\
\text { Sig. (2-tailed) }\end{array}$ & $\begin{array}{l}0.177 \\
0.078 \\
\end{array}$ \\
\hline
\end{tabular}

\section{REFERENCES}

Bahrami, M. A., Chalak, M., Montazeralfaraj, R., \& Tafti, A. D. (2014). Iranian nurses' perception of patient safety culture. Iranian Red Crescent Medical Journal, 16(4).

Bondevik GT, Hofoss D, Husebo BS, Deilkas EC. Patient safety culture in Norwegian nursing homes. BMC health services research. 2017 Dec;17(1):1-0

El-Jardali, F., Dimassi, H., Jamal, D., Jaafar, M., \& Hemadeh, N. (2011). Predictors and outcomes of patient safety culture in hospitals. BMC health services research, 11(1), 1-12.

Elsous, A., Akbarisari, A., Rashidian, A., Aljeesh, Y., Radwan, M., \& Zaydeh, H. A. (2017).
Psychometric properties of an Arabic safety attitude questionnaire (short form 2006). Oman medical journal, 32(2), 115.

Gunawan D, Hariyati RT. The implementation of patient safety culture in nursing practice. Enfermeria clinica. 2019 Sep 1;29:139-45.

Jeffs, L., Baker, G. R., Taggar, R., Hubley, P., Richards, J., Merkley, J., ... \& Fong, J. H. (2018). Attributes and Actions Required to Advance Quality and Safety in Hospitals: Insights from Nurse Executives. Nursing Leadership (Toronto, Ont.), 31(2), 20-31.

Kangasniemi, M., Vaismoradi, M., Jasper, M., \& Turunen, H. (2013). Ethical issues in patient 
safety: Implications for nursing management. Nursing ethics, 20(8), 904-916.

Kim, J., An, K., Kim, M. K., \& Yoon, S. H. (2007). Nurses' perception of error reporting and patient safety culture in Korea. Western journal of nursing research, 29(7), 827-844.

Lee, W. C., Wung, H. Y., Liao, H. H., Lo, C. M., Chang, F. L., Wang, P. C., ... \& Hou, S. M. (2010). Hospital safety culture in Taiwan: a nationwide survey using Chinese version safety attitude questionnaire. BMC health services research, 10(1), 1-8.

Li, Y., Zhao, Y., Hao, Y., Jiao, M., Ma, H., Teng, B., ... \& Qiao, H. (2018). Perceptions of patient safety culture among healthcare employees in tertiary hospitals of Heilongjiang province in northern China: a cross-sectional study. International Journal for Quality in Health Care, 30(8), 618623.

Nieva, V. F., \& Sorra, J. (2003). Safety culture assessment: a tool for improving patient safety in healthcare organizations. BMJ quality \& safety, 12(suppl 2), ii17-ii23.

Rowland, P., \& Kitto, S. (2014). Patient safety and professional discourses: implications for interprofessionalism. Journal of Interprofessional Care, 28(4), 331-338.

Sammer, C. E., Lykens, K., Singh, K. P., Mains, D. A., \& Lackan, N. A. (2010). What is patient safety culture? A review of the literature. Journal of nursing scholarship, 42(2), 156-165.

Sexton, J. B., Thomas, E. J., \& Grillo, S. P. (2003). The Safety Attitudes Questionnaire guideline for administration. Texas: The University of Texas Center of Excellence for Patient Safety Research and Practice.

Sharour, L. A., Suleiman, K., \& Al-Ghabeesh, S. (2018). Toward having safe environment in critical care units: a multisite study. Crit Care, 21(4), 168-173.

Tavares SP, Moura EC, Avelino FB, Lopes VC, Nogueira LT.(2018). Cultura de segurança do paciente na perspectiva da equipe de enfermagem. Rev Rene,(19)., 3152.

Tirgar, A., Hosseinabadi, M. B., Ahmadi, O., Sadeghi, M., Jafarpoor, H., \& Samaei, S. E. (2018). Safety
Attitude and Its Predictor Individual and Organizational Variables among Nurses: A Cross-Sectional Study. International Journal of Occupational Hygiene, 10(1), 12-18.

Tondo JC, Guirardello ED. Perception of nursing professionals on patient safety culture. Revista brasileira de enfermagem. 2017 Dec;70(6):128490.

Vincent, C., Taylor-Adams, S., \& Stanhope, N. (1998). Framework for analysing risk and safety in clinical medicine. Bmj, 316(7138), 1154-1157.

Waterson, P. (Ed.). (2018). Patient safety culture: Theory, methods and application. CRC Press.

Weaver, S. J., Lubomksi, L. H., Wilson, R. F., Pfoh, E. R., Martinez, K. A., \& Dy, S. M. (2013). Promoting a culture of safety as a patient safety strategy: a systematic review. Annals of internal medicine, 158(5_Part_2), 369-374.

Zarei, M. (2014). Patient Safety Culture: Nurses' Attitude in Marvdasht Shahid Motahary Hospital, 1392. Middle East Afr. J. Ophthalmol, 2(1), 5357. 